\title{
INFLUENCE OF PANDANUS TECTORIUS LEAF FIBER ON MECHANICAL PROPERTIES AND MORPHOLOGY OF POLYPROPYLENE COMPOSITE
}

\author{
Fajar Nugroho, Sudarmanto
}

Program Studi Teknik Mesin Sekolah Tinggi Teknologi Adisutjipto

Jl. Janti Blok R Lanud Adisutjipto Yogyakarta. 55198

mas_noeg@yahoo.com

\begin{abstract}
Natural fiber reinforced polymer composites are widely developed because of their relative low price and eco-friendly. One of natural fiber sourches is pandanus tectorius leaf. This study aimed to determine the effect of variations in fiber volume fraction on tensile strength, impact strength, bending strength and morphological on sea pandanus fiberspolypropylene composites. Tensile test spesimen refer to ASTMD 638, impact test spesimen refes to ASTMD 5942-96, bending test spesimen refer to ASTMD 790 -02. The increasing of the volume fraction increased the tensile strength and impact strength. The tensile test results showed the highest tensile strength results for composites with a volume fraction of $35 \%$ was $25.82 \mathrm{MPa}$. The impact test results showed that the highest impact strength was obtained in the $35 \%$ volume fraction of 0.0062 Joule/mm2. The bending test results showed that the highest bending strength was obtained in the 20\% volume fraction of $24.96 \mathrm{MPa}$. Based on SEM test results, there were voids, cracks, fibers pull out on the composite.
\end{abstract}

Keyword : fiber-polypropylene composites, tensile strength, impact strength, bending strength, morpological composite.

Abstrak

Komposit polimer dengan penguat serat alam sekarang banyak dikembangkan karena harga yang relatif murah dan ramah lingkungan. Salah satu sumber serat alam adalah daun pandan laut.Tujuan dari penelitian ini adalah untuk mengetahui pengaruh fraksi volume serat terhadap kekuatan tarik, kekuatan impak, kekuatan bending dan morfologi komposit. Spesimen uji tarik mengacu pada ASTMD 638, Spesimen uji impak mengacu pada ASTMD 5942-96 dan speimen uji Bending mengacu pada ASTMD 790-02. Variasi fraksi volume berpengaruh terhadap kekuatan tarik, impak bending dan morfologi patahan. Dari hasil pengujian tarik didapatkan hasil kekuatan tarik tertinggi dari komposit dengan fraksi volume $35 \%$ sebesar 25,82 MPa. Kekuatan impak tertinggi pada fraksi volume 35\% sebesar 0,0062 Joule/mm2. Hasil uji bending diperoleh kekuatan bending tertingi pada fraksi volume $20 \%$ sebesar 24,96 MPa. Berdasarkan hasil pengujian SEM terlihat adanya void, crack, fiber pull out pada komposit.

Kata kunci : komposit propilena-serat, kekuatan tarik, kekutan impak, kekuatan bending, morfologi komposit.

\section{Pengantar}

Komposit merupakan suatu material unik yang terdiri dari dua material atau lebih yang menghasilkan sifat lebih baik (lebih kuat, tangguh, tahan lama). Komposit memiliki banyak keunggulan seperti ringan, kuat, tidak terkorosi, tidak magnetik dan dapat di rancang kekuatan maupun kekakuannya sesuai kebutuhan. Komposit terdiri dari dua komponen utama, yaitu matriks yang bersifat ulet dan penguat atau serat yang bersifat kuat dan getas.

Sifat mekanik komposit yang diperkuat serat tergantung pada hubungan antarmuka serat-matriks, kemampuan serat untuk transfer beban ke matriks dan sebaliknya. Sifat hidrofil yang dimiliki serat alam merupakan tantangan utama dalam penggunaannya pada komposit 
bermatriks polimer dimana dapat menyebabkan kompatibilitas yang kurang baik antara serat dan matriks. Sifat hidrofil ini menyebabkan serat dapat menyerap air atau uap air, mengakibatkan perubahan dimensi serat yang menjadi langkah awal retaknya komposit sehingga sifat mekaniknya menurun. Dalam hal ini, dibutuhkan perlakuan kimia untuk meningkatkan sifat serat alam seperti yang sudah dilakukan oleh peneliti sebelumnya $[1,2]$. Selanjutnya serat alam sebagai penguat dalam komposit dapat menhasilkan kekuatan mekanik yang baik serta dapat digunakan pada berbagai aplikasi[3,4,5].

Polimer merupakan bahan ideal sebagai matriks dalam komposit disebabkan kemudahan untuk diproses, ringan dan sifat mekaniknya cukup baik. Termoplastik memiliki banyak kelebihan diantaranya harganya relatif murah dan mudah dibentuk pada suhu tinggi. Polipropilena merupakan salah satu jenis termoplastik yang banyak digunakan sebagai matriks pada bahan komposit, termasuk pada aplikasi otomotif.

Dewasa ini, serat alam digunakan secara ekstensif menggantikan serat gelas dan serat sintetis lainnya pada material komposit. Pandan laut (pandanus tectorius) merupakan anggota suku Pandanaceae yang memiliki kemampuan untuk mengontrol erosi pada kawasan pantai, sebagai pemecah angin dan penanda garis pantai. Tanaman ini banyak dijumpai di kawasan Asia Selatan dan Timur sampai ke Polinesia. Daun pandan laut sampai saat ini dimanfaatkan sebagai bahan kerajinan seperti pembuatan tikar, topi, dan lain-lain [1]. Dalam beberapa dekade terakhir, komposit polimer diperkuat serat alam telah menjadi perhatian banyak peneliti di dunia. Walaupun daun pandan laut ini tersedia sangat banyak di alam, namun belum banyak penelitian yang membahas daun pandan laut sebagai serat pada bahan komposit. Oleh karena itu, penelitian lebih lanjut mengenai pemanfaatan pandan laut dalam aplikasi teknik perlu dilakukan.

Kebutuhan akan material ramah lingkungan menyebabkan banyak peneliti di dunia yang berfokus pada pengembangan material baru yang akan meningkatkan kualitas produk dengan tidak mengabaikan faktor lingkungan. Kebutuhan green material ini membawa kepada penggunaan komposit yang terbuat dari serat alam dengan matriks berbahan polimer. Komposit jenis ini merupakan material yang paling banyak diteliti beberapa tahun terakhir. Komposit serat alam merupakan bahan alternatif pengganti serat sintetik, yang bersifat berbahaya terhadap lingkungan, dan dapat membantu mengontrol masalah polusi. Sebagai tambahan, komposit serat alam memiliki banyak kelebihan seperti biaya rendah, memiliki sifat mekanik lebih baik dan membutuhkan konsumsi energi yang cukup kecil. Di samping itu, penggunaan material ini pada aplikasi struktur dapat meningkatkan ketahanannya sehingga dapat mengurangi limbah konstruksi.

Banyak serat yang tersedia di alam yang dapat digunakan sebagai penguat matriks polimer seperti flax, hemp, jute, sisal, isora, ferula, okra, ferula dan coir [7-10]. Banyak industri otomotif menggunakan serat selulosa menggantikan serat konvensional seperti serat gelas dan karbon sebagai penguat pada komposit [11, 12]. Bagaimanapun, komposit berbahan serat alam memiliki beberapa kekurangan, seperti ketidak stabilan pada suhu tinggi, penyerapan uap air yang dapat merusak komposit [13], ketidak stabilan dimensi akibat penyerapan uap air [14]. Hal ini disebabkan oleh struktur di dalam serat alam itu sendiri. Selulosa, hemiselulosa, pectin dan lignin merupakan unsur pokok penyusun serat alam. Bahan alam yang kaya akan grup hydroxy-1 memiliki ikatan yang kuat dengan kelembaban dan meyebabkannya bersifat hidrofilik atau dapat berikatan dengan air [15].

Di sisi lain, matriks yang biasa digunakan sebagai bahan komposit adalah polymer seperti polypropylene, polyvinyl chloride dan polylactic acid yang memiliki sifat hidrofobik atau tidak dapat berikatan dengan air $[14,16]$. Perbedaan sifat yang cukup signifikan antara serat alam yang dapat berikatan dengan air dan matriks polimer yang tidak berikatan dengan air menyebabkan hubungan antarmuka (interface bonding) yang kurang baik antar kedua material ini jika digabungkan menjadi suatu material seperti komposit. Interface bonding 
yang kurang baik ini yang akan menyebabkan turunnya sifat mekanik komposit. untuk memperbaiki hal ini, dilakukan treatment (perlakuan) baik pada serat maupun pada matriks. Perlakuan kimia diuji oleh beberapa peneliti untuk memperbaiki sifat komposit polimer/serat alam dengan meningkatkan kompabilitas antara serat dan matriks $[17,18]$.

\section{Metodologi Penelitian}

Daun pandan laut dipotong $50 \mathrm{~cm}$ kemudian ditimbang 100 gram dan dicuci bersih. Selanjutnya daun diekstraksi dengan direbus pada suhu 100 derajat Celcius selama 1 jam pada larutan $\mathrm{NaOH}$ (alkali) dengan konsentrasi 6 persen. Lalu, serat didinginkan pada suhu ruangan, dicuci dengan air mengalir dan direndam dalam aquades dengan tambahan asam asetat 1 persen. Serat kemudian dikeringkan pada suhu 60 derajat Celcius selama 3 jam. Setelah kering, serat dipotong menjadi ukuran 5 mikrometer dan ditimbang sesuai dengan variasi massa dan dibagi menjadi 30 bagian. Plastik polipropilena berupa lembaran dipotong sesuai ukuran cetakan yang berbentuk balok (panjang $170 \mathrm{~mm}$ lebar $22 \mathrm{~mm}$ ) sebanyak 32 lembar per komposit. Satu lembar plastik dimasukkan ke dalam cetakan (Gambar 1), diikuti dengan serat, kemudian plastik dan seterusnya sampai terbentuk 30 lapisan. Cetakan ditutup dan ditekan sebesar 26 bar. Kemudian cetakan dipanaskan sampai suhu 170 derajat Celcius selama 3 menit. Pemanas dimatikan dan cetakan ditunggu sampai dingin pada suhu ruangan kemudian spesimen dikeluarkan dari cetakan. Proses diulangi dengan variasi fraksi volume serat 20, 25, 30, 35, dan 40 persen. Pengujian tarik, bending dan impak dengan masingmasing 5 buah spesimen uji dilakukan untuk mengetahui sifat mekanik komposit sedangkan pengujian SEM dilakukan untuk mengetahui morfologi patahan hasil pengujian tarik. Pengujian tarik, bending dan impak masing-masing dilakukan sesuai standar ASTM D 63802, D 790-02 dan D5942-96.
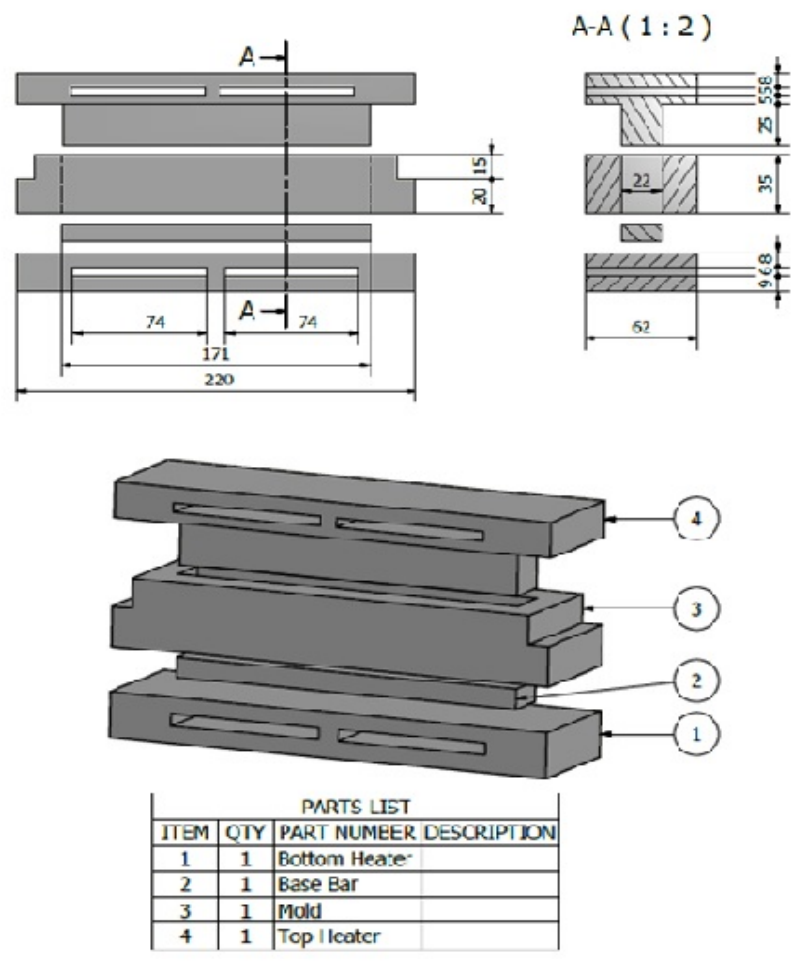

Gambar 1. Desain Cetakan Komposit 


\section{Hasil dan Pembahasan}

Hasil Uji Tarik

Hasil pengujian tarik terhadap spesimen komposit penguat serat daun pandan laut dengan matriks plastik polipropilena dapat dilihat seperti pada Gambar 2.

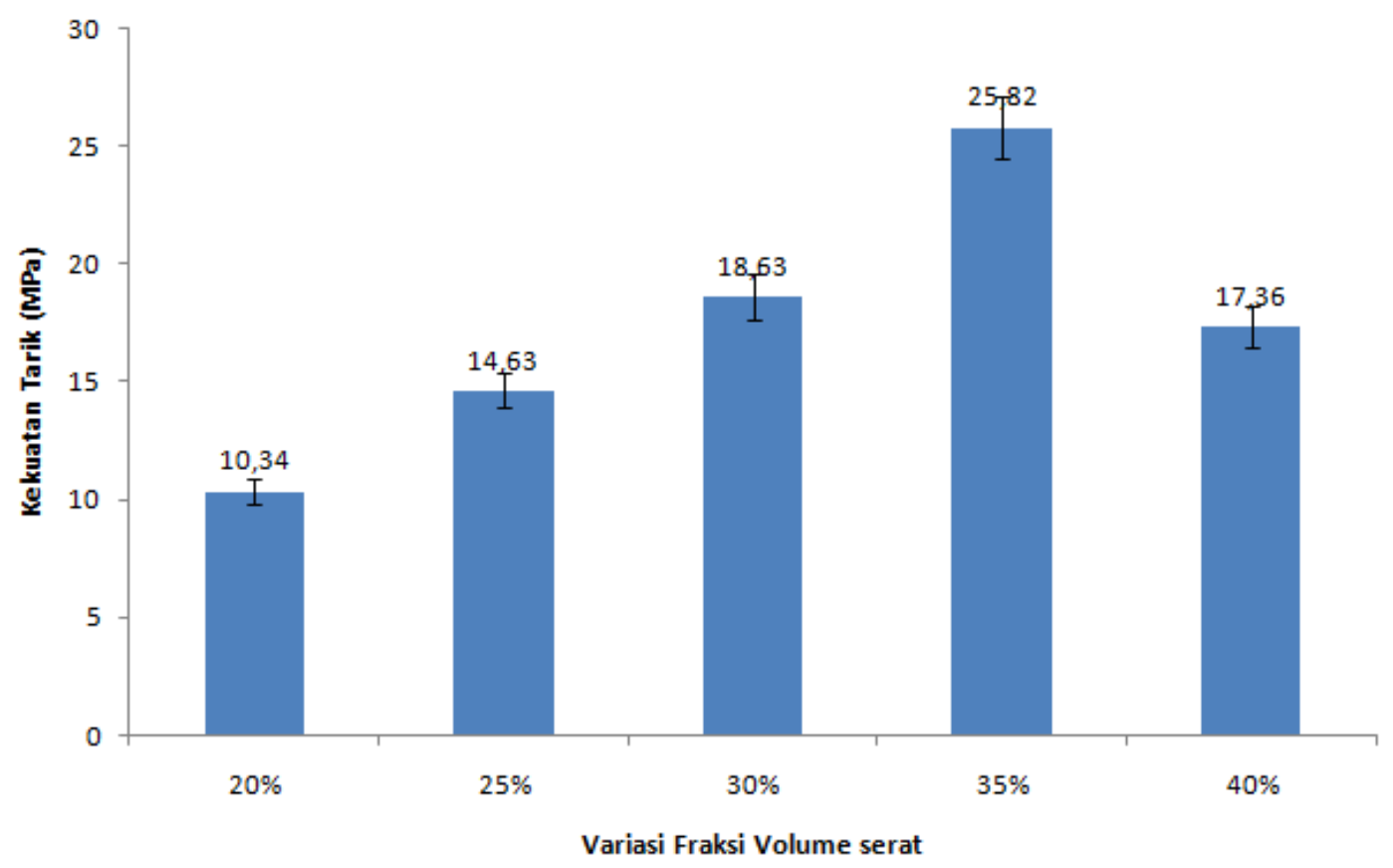

Gambar 2. Kekuatan komposit Serat Pandan laut - Polipropilena

Dari hasil pengujian tarik komposit polipropilena dengan variasi fraksi volume serat $20 \%, 25 \%, 30 \%, 35 \%$, dan $40 \%$ ditunjukan pada Gambar 2. Pada hasil pengujian tarik yang telah dilakukan dapat dilihat dari variasi fraksi volume serat $20 \%$ mempunyai kekuatan tarik rata-rata sebesar 10,34 $\mathrm{MPa}$, fraksi volume $25 \%$ mempunyai kekuatan tarik rata-rata sebesar $14,63 \mathrm{MPa}$, fraksi volume 30\% mempunyai kekuatan tarik rata-rata sebesar 18,63 MPa,fraksi volume $35 \%$ mempunyai kekuatan tarik rata-rata sebesar $25,82 \mathrm{MPa}$, dan variasi fraksi volume $40 \%$ mempunyai kekuatan tarik rata-rata sebesar 17,36 $\mathrm{MPa}$. Dari hasil pengujian yang dilakukan diperoleh kekuatan tarik tertinggi yaitu fraksi volume 35\% dengan kekuatan tarik sebesar 25,82 MPa dan kekuatan tarik terendah diperoleh dari variasi fraksi volume $20 \%$ dengan kekuatan tarik 10,34 MPa. Dari data yang diperoleh maka dapat dilihat bahwa dengan meningkatnya jumlah serat hingga pada jumlah tertentu akan meningkatkan kekuatan tarik dari komposit yang dihasilkan[18, 19].

Peningkatan variasi fraksi volume serat dapat meningkatkan kekuatan tarik komposit polipropilena karena persebaran serat daun pandan laut merata dan komposisi matriks dengan serat seimbang sehingga kekuatan tarik dengan fraksi 35\% memiliki kekuatan tarik tertinggi. Pada variasi fraksi volume $40 \%$ terjadi penurunan dikarenakan komposisi serat yang tidak seimbang dengan matriksnya sehingga matriks yang berfungsi sebagai pengikat serat tidak dapat mengikat serat secara maksimal sehingga kekuatan tarik yang terjadi pada fraksi volume $40 \%$ menurun. Gaya ikat antara matriks dan serat sangat penting untuk mengurangi gejala fiber pull out dan mempertinggi tegangan yang bisa diteruskan dari matriks ke serat yang berfungsi sebagai penguat. 
Hasil Uji Impak

Hasil pengujian impak terhadap spesimen komposit penguat serat daun pandan laut dengan matriks plastik polipropilena dapat dilihat seperti pada Gambar 3. Pada komposit dengan fraksi volume $20 \%$ serat pandan laut mempunyai harga impak $0,0036 \mathrm{Joule} / \mathrm{mm}^{2}$, fraksi volume $25 \%$ mempunyai harga impak 0,0046 Joule $/ \mathrm{mm}^{2}$, Fraksi volume $30 \%$ mempunyai harga impak $0,0049 \mathrm{Joule} / \mathrm{mm}^{2}$, dan pada fraksi volume $40 \%$ mempunyai harga impak 0,0061 Joule/mm². Dari Gambar 3 dapat dilihat bahwa kekuatan impak memiliki kencenderungan untuk menungkat dengan bertambahnyan serat pandan laut pada matrik propilena.

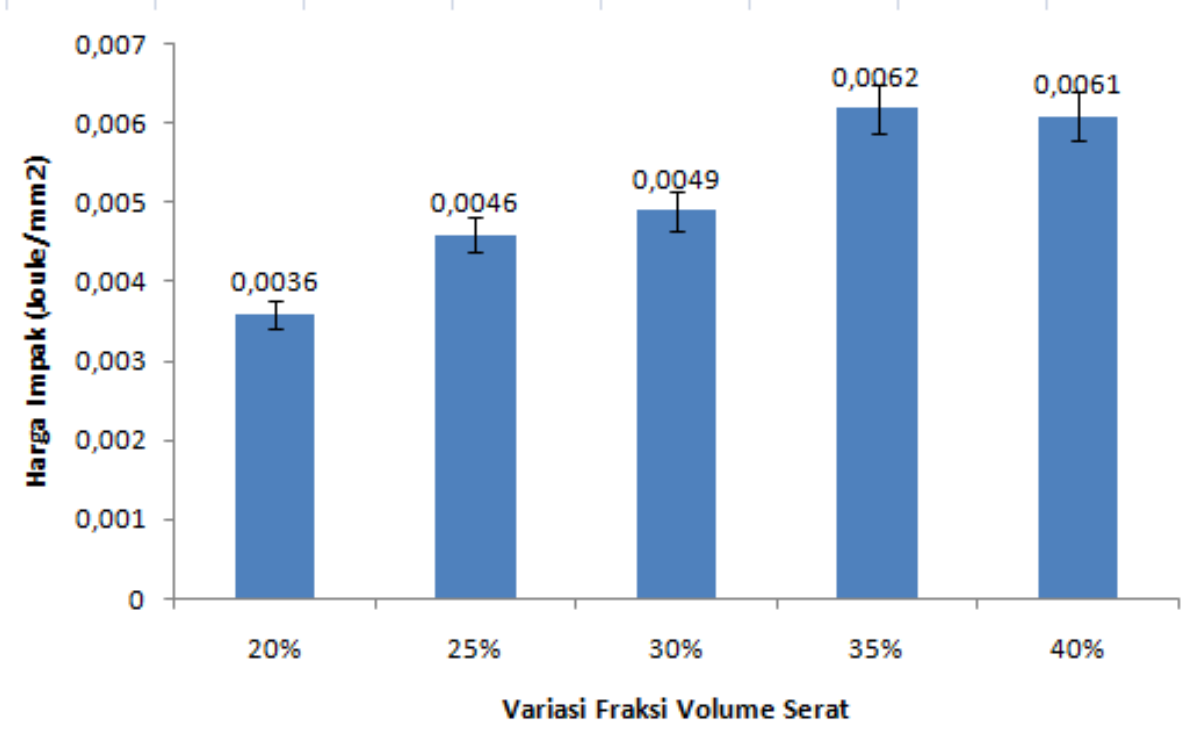

Gambar 3. Hasil Uji Impak Komposit Serat Pandan Laut-Propilena

Hasil Uji Bending.

Hasil pengujian impak terhadap spesimen komposit penguat serat daun pandan laut dengan matriks plastik polipropilena dapat dilihat seperti pada Gambar 4.

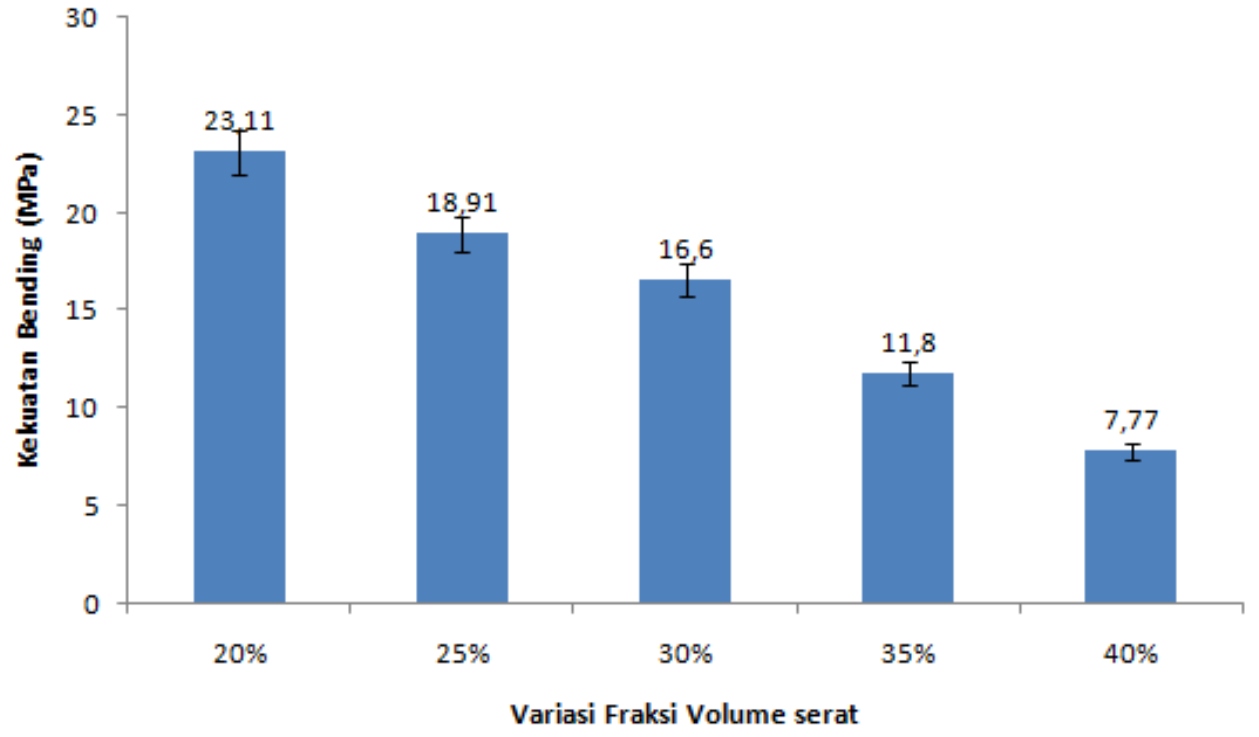

Gambar 4. Hasil Uji Bending Komposit Serat Pandan Laut-Propilena 
Gambar 4. menunjukan pada fraksi volume $20 \%$ serat pandan laut mempunyai kekuatan bending $23,11 \mathrm{MPa}$, pada fraksi volume $25 \%$ serat pandan laut mempunyai kekuatan bending 18,91 MPa, pada fraksi volume $30 \%$ serat pandan laut mempunyai kekuatan bending ebesar $16,6 \mathrm{MPa}$. pada fraksi volume $35 \%$ serat pandan laut mempunyai kekuatan bending sebesar $11,8 \mathrm{MPa}$ dan pada fraksi volume $40 \%$ serat pandan laut mempunyai kekuatan bending sebesar 7,77 MPa. Kekuatan bending yang dihasilkan memiliki kecenderungan menurun seiring dengan semakin besarnya jumlah kandungan serat daun pandan laut dalam komposit. Semakin besar kandungan serat berarti jumlah propilena dalam komposit semakin kecil. Kekuatan lentur komposit bermatrik propilena akan sangat ditentukan oleh matrik propilena sendiri. Dengan demikian penurunan kekuatan bending dari komposit serat daun pandan laut-propilena adalah wajar jika dilihat dari unsur penyusun kompositnya.

Hasil Foto Sem

Hasil foto sem dapat dilihat pada Gambar 5. berikut ini.

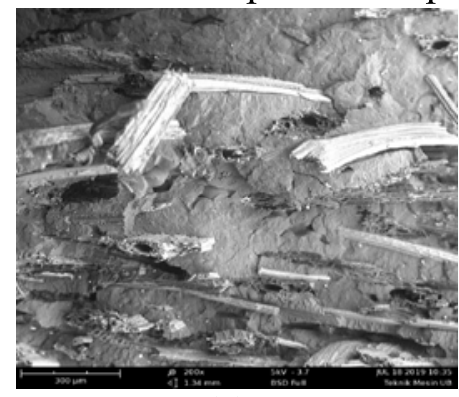

(a)

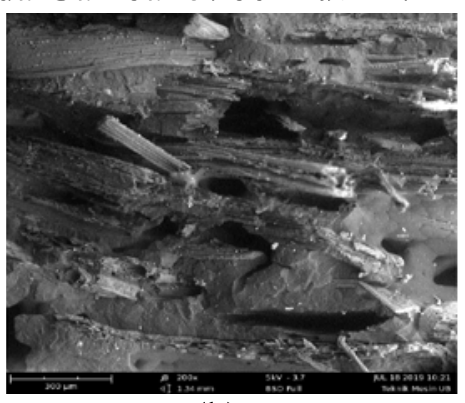

(b)

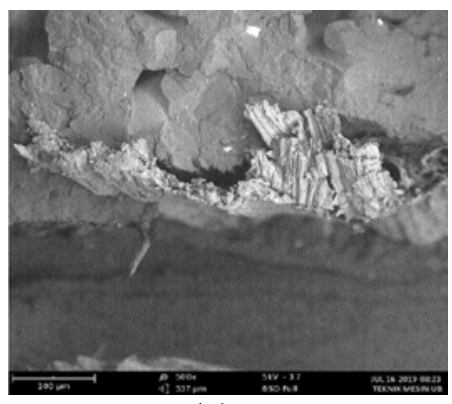

(c)

Gambar 5. Foto SEM penampang patahan spesimen dari (a) Uji Tarik, (b) Uji Impak. (c).Uji Bending

Dari hasil pengujian SEM pada Gambar 5 terhadap penampang patahan spesimen uji tarik, uji impak dan uji bending pada komposit serat daun pandan laut-polipropilena terdapat fiber pull out akibat dari pengaruh beban tarik, beban kejut dan beban lentur pada saat pengujian mekanis komposit. Pada saat beban dikenakan ke komposit, beban akan ditahan serat dan matrik secara bersama-sama. Lemahnya ikatan yang terbentuk menyebabkan ikatan antara serat dan matrik lepas sebelum serat atau matriks patah. Selain terdapat mekanisme pull out dalam material komposit juga terdapat void.

Selain itu, jumlah void yang sedikit dan serat daun pandan laut yang dapat menahan tegangan tarik yang terjadi pada komposit dapat meningkatkan kekuatan tarik. Sedangkan, kekuatan tarik terendah terjadi akibat persebaran serat yang tidak merata dan komposisi matriks dengan serat yang tidak seimbang sehingga saat plastik mencair serat yang sudah tercampur didalam plastik akan bergeser mengikuti arah mencairnya plastik yang mengakibatkan penumpukan serat pada beberapa daerah di dalam komposit dan mengakibatkan void atau rongga udara yang terjadi pada komposit. Akibat dari persebaran serat yang tidak merata dan banyaknya void atau rongga udara menyebabkan interaksi antara serat dengan matriks berkurang sehingga ikatan anatar muka antara serat daun pandan laut dengan polipropilena menjadi rendah. Keterbatasan berbagai teknologi fabrikasi dan proses parameter yang menghasilkan beberapa cacat internal yang tidak diinginkan di dalam komposit, seperti rongga, delaminasi, dan miskin matriks atau kaya matriks. Cacat ini memiliki distribusi tegangan efek pada bahan/struktur sendiri atau bersama, yang dapat melemahkan sifat mekanik komposit [20, 21, 22]. 
Ukuran void yang dihasilkan sangat beragam tergantung dari interaksi permukaan yang terbentuk antara serat daun pandan laut dengan propilena yang berfungsi sebagai pengikat serat. Void yang terdapat di dalam komposit tersebut menyebabkan luasan permukaan yang menahan beban pada saat pengujian tarik dan impak menjadi semakin kecil sehingga akan menyebabkan kekuatannya menurun. Campuran homogen antara matriks dan pengisi terbentuk sehingga kekuatan tarik optimal [21,22].

\section{Kesimpulan}

Kekuatan tarik dan harga impak komposit serat daun pandan laut - polipropilena meningkat dengan meningkatnya jumlah serat daun pandan laut di dalam komposit yang dihasilkan, namun meningkatnyan kekuatan tarik akan mencapai nilai optimal sampai pada fraksi volume $35 \%$ kemudian akan turun pada fraksi volume $40 \%$. Namun kekuatan bending komposit serat daun pandan laut-propilena sangat ditentukan oleh jumlah matrik propilena, semakin sedikit jumlah matrik yang digunakan dan semakin besar jumlah serat daun pandan yang ditambahkan maka kekuatan bending komposit yang dihasilkan akan semakin turun. Dari foto SEM dapat dilihat adanya kegagalan interaksi antarmuka berupa fiber pull out, crack dan void di dalam komposit serat daun pandan laut - propilena.

\section{Daftar Pustaka}

[1] Alvarez, V. A., Fraga, A. N., \& Vazquez, A. (2004). Effects of the moisture and fiber content on the mechanical properties of biodegradable polymer-sisal fiber biocomposites. Journal of Applied Polymer Science, 91(6), 4007-4016.

[2] Sosiati, H., Pratiwi, H., \& Wijayanti, D. A. (2015). The Influence of Alkali Treatments on Tensile Strength and Surface Morphology of Cellulose Microfibrils. In Advanced Materials Research (Vol. 1123, pp. 147-150). Trans Tech Publications.

[3] Sanjay, M. R., Madhu, P., Jawaid, M., Senthamaraikannan, P., Senthil, S., \& Pradeep, S. (2018). Characterization and properties of natural fiber polymer composites: A comprehensive review. Journal of Cleaner Production, 172, 566-581.

[4] Elanchezhian, C., Ramnath, B. V., Ramakrishnan, G., Rajendrakumar, M., Naveenkumar, V., \& Saravanakumar, M. K. (2018). Review on mechanical properties of natural fiber composites. Materials Today: Proceedings, 5(1), 1785-1790.

[5] Sailesh, A., Arunkumar, R., \& Saravanan, S. (2018). Mechanical Properties and Wear Properties of Kenaf-Aloe Vera-Jute Fiber Reinforced Natural Fiber Composites. Materials Today: Proceedings, 5(2), 7184-7190.

[6] Thomson, L. A., Englberger, L., Guarino, L., Thaman, R. R., \& Elevitch, C. R. (2006). Pandanus tectorius (pandanus). Species profiles for Pacific Island agroforestry.

[7] Fávaro, S. L., Lopes, M. S., de Carvalho Neto, A. G. V., de Santana, R. R., \& Radovanovic, E. (2010). Chemical, morphological, and mechanical analysis of rice husk/post-consumer polyethylene composites. Composites Part A: Applied Science and Manufacturing, 41(1), 154-160.

[8] Xie, Y., Hill, C. A., Xiao, Z., Militz, H., \& Mai, C. (2010). Silane coupling agents used for natural fiber/polymer composites: A review. Composites Part A: Applied Science and Manufacturing, 41(7), 806-819.

[9] Alamri, H., \& Low, I. M. (2012). Effect of water absorption on the mechanical properties of $\mathrm{n}-\mathrm{SiC}$ filled recycled cellulose fibre reinforced epoxy eco-nanocomposites. Polymer Testing, 31(6), 810-818. 
[10] Scalici, T., Fiore, V., \& Valenza, A. (2016). Effect of plasma treatment on the properties of Arundo Donax L. leaf fibres and its bio-based epoxy composites: A preliminary study. Composites Part B: Engineering, 94, 167-175.

[11] Yan, L., Chouw, N., Huang, L., \& Kasal, B. (2016). Effect of alkali treatment on microstructure and mechanical properties of coir fibres, coir fibre reinforced-polymer composites and reinforced-cementitious composites. Construction and Building Materials, 112, 168-182.

[12] Ardanuy, M., Claramunt, J., \& Toledo Filho, R. D. (2015). Cellulosic fiber reinforced cement-based composites: A review of recent research. Construction and building materials, 79, 115-128.

[13] Sawsen, C., Fouzia, K., Mohamed, B., \& Moussa, G. (2015). Effect of flax fibers treatments on the rheological and the mechanical behavior of a cement composite. Construction and Building Materials, 79, 229-235.

[14] Punyamurthy, R., Sampathkumar, D., Ranganagowda, R. P. G., Bennehalli, B., \& Srinivasa, C. V. (2017). Mechanical properties of abaca fiber reinforced polypropylene composites: Effect of chemical treatment by benzenediazonium chloride. Journal of King Saud University-Engineering Sciences, 29(3), 289-294.

[15] Faruk, O., Bledzki, A. K., Fink, H. P., \& Sain, M. (2012). Biocomposites reinforced with natural fibers: 2000-2010. Progress in polymer science, 37(11), 1552-1596.

[16] Qian, S., Wang, H., Zarei, E., \& Sheng, K. (2015). Effect of hydrothermal pretreatment on the properties of moso bamboo particles reinforced polyvinyl chloride composites. Composites Part B: Engineering, 82, 23-29.

[17] Di Bella, G., Fiore, V., \& Valenza, A. (2010). Effect of areal weight and chemical treatment on the mechanical properties of bidirectional flax fabrics reinforced composites. Materials \& Design, 31(9), 4098-4103.

[18] Sood, M., \& Dwivedi, G. (2018). Effect of fiber treatment on flexural properties of natural fiber reinforced composites: A review. Egyptian journal of petroleum, 27(4), 775-783.

[19] Mardiyati, M., Rizkiansyah, R. R., \& Purnomo, I. (2016). Sifat Mekanik Komposit Polipropilena Berpenguat Serat Sansevieria Unidirectional. Mesin, 25(2), 73-82.

[20] Pratiwi, H. (2016, November). The Effects of Mixing and Curing on Morphological and Mechanical Properties of Epoxy-Albasia Composites. In Conference SENATIK STT Adisutjipto Yogyakarta (Vol. 2, pp. 55-61).

[21] Pratiwi, H. (2018). Influence of Albasia Wood on Mechanical Properties and Morphology of Epoxy Composites. Angkasa: Jurnal Ilmiah Bidang Teknologi, 10(2), 116-121.

[22] Nugroho, F. (2016, November). Studi Pengaruh Proses Manufaktur Komposit Bermatrik Epoksi Terhadap Kekuatan Tarik dan Impak pada Komposit Hybrid Berpenguat Serbuk Kayu Albasia dan Serat Gelas. In Conference SENATIK STT Adisutjipto Yogyakarta (Vol. 2, pp. 41-47). 